\title{
ICT-related skills and needs of blind and visually impaired people
}

\author{
Carolina van Puffelen \\ University of Twente, Dpt. of Technical \& Professional Communication, The Netherlands \\ m.c.j.vanpuffelen@utwente.nl
}

\begin{abstract}
:
This study focuses on the relationship between the ICT-related training offered to blind and visually impaired people and their actual, self-reported and demonstrated, competencies for online activities and information processing. The findings of the study can shed light on how people with severe visual disabilities are prepared to access the web for educational, institutional and social participation. The study also gives insight in the validity of instruments to measure ICT-linked skills for the target group and creates an empirical foundation for improvements of ICT-related training. The first phase of the study investigated how blind and visually impaired people perceive their participation in society through ICT. An extensive interview showed how this audience perceives the frequency and quality of their Internet use (or absence thereof) and how they acquired these skills.
\end{abstract}

\section{Introduction}

In the Netherlands blind or visually impaired people can obtain a formal ICT training from one of the three Dutch support organizations for people with a visual impairment. The trainings usually consist of tailor-made instructions fitted to the individual supporting that person in participating in society through ICT-use. The organizations for which these trainings are an integral part of their rehabilitation support are interested in an assessment of the effects. They want to know whether they are of good quality and whether they fit the needs of their audience which consists of young and elderly people with a severe visual disability.

\section{Related Work}

The study is related to other studies on access and ICT-skills conducted in the Netherlands $[1,2]$. These studies examine ICT-linked participation and skills assessments for Dutch people without a specific visual disability. In this sense the study forms part of a larger effort to chart the Dutch population on these aspects.

\section{Motivation}

There is a considerable body of research on visually impaired people that concentrates on access technologies and web designs. This study starts 'from the other side' by looking mainly into the question what this audience needs to make good use of these facilities. We depart from a situation in which a visually disabled person has a computer with supportive devices and online access only to discover that he or she has or lacks adequate skills to navigate the Web and process online information. With this study we hope to contribute to an integrated view on accessibility from which we can fruitfully reduce the barriers that people with a visual disability face everyday. 


\section{Background to the study}

In many studies it has been demonstrated that ICT is not only reducing barriers of access, but at the same time creating barriers $[3,4,5,6]$. People with visual disabilities face special barriers in using the Internet, aside from those related to material access and computerrelated trainings. Dobransky and Hargittai [7] mention technical accessibility problems as one of the extra barriers that people with a visual disability need to tackle. Bayer and Pappas [8] found that especially navigation and screen reading posed problems for blind internet users.

For a large majority of people with visual disabilities ICT-related training forms an integral part of their rehabilitation effort. The purpose of the present study is to investigate whether these ICT trainings empower them to overcome the mental and technical ICT-barriers and to participate online in educational, social and institutional activities.

One of the specific issues addressed in this research is the measurement of ICT- skills. Many studies on digital literacy measure the skills involved with self-report measures such as questionnaires. Hargittai $[9,10]$ has shown that there can be a severe mismatch between people's perceived and actual, demonstrated ICT-skills leading to over-estimates as well as under-estimates. The present study includes self-reports as well as observations of actual behaviour. Thus, it seeks to contribute to developing valid quick-scan assessment of people's ICT competence. The findings should also form a foundation for further improvement of the ICT-related training for young and elderly people with visual disabilities.

\section{Research questions}

The target groups in our study are young (10-14 years) and elderly (55+) people with a vision of $<0.3$. Young visually disabled need ICT skills for communication as well as for entering the labor market and for expanding their educational opportunities. For elderly people with visual disabilities ICT-skills are important to get and stay in touch with peer groups, with government institutions, and with services related to their disabilities. Using Van Dijk's [1] framework for analyzing digital inequality, the study focuses on: (1) Educational participation, (2) Social participation, and (3) Institutional participation. In these areas of participation we concentrate on the following activities that our audience is likely to engage in, or might want to do so: emailing and chatting, information seeking and conducting transactions online. We seek to find an answer to the following research questions:

- How do people with a visual disability assess their skill levels in educational, social and institutional areas of participation?

- Which audience characteristics are related to the skill levels?

- How have people with a visual disability acquired their skills?

- Which types of ICT-enabled tasks do visually disabled people engage in, or aspire to engage in?

- Which barriers do visually disabled people encounter when performing key ICTsupported tasks in the three areas of participation? 


\section{Research instrument}

The key skills that we examine in this study are: (a) synchronous and a-synchronous communication skills (use of e-mail and chat), (b) Information search and retrieval in websites (use of static web pages), and (c) Conducting transactions in websites (use of forms in dynamic web pages and web services).A list of key skills components in each area of participation is developed. This list forms the basis for conducting a telephone interview with people with visual impairments. The pre-structured skills interview designed for this study is based on the types of access and digital skills described by van Dijk [1].

He distinguished four successive kinds of access to computers and internet connections: motivational access, material or physical access, skills access and usage access.

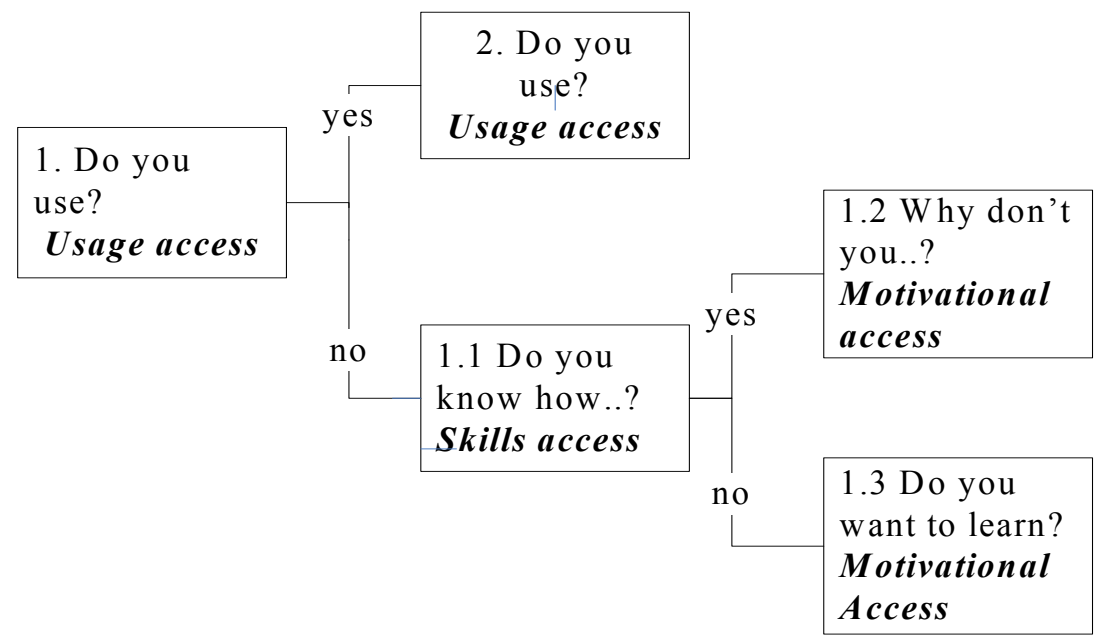

Figure 1. ICT skills access questions

\section{Respondents}

Participants are recruited through the three national support organizations. The inclusion criteria are: a vision of $<0.3$ and having received ICT training from these organizations in the past three years. All participant information will be treated in accordance with the professional code of conduct for social researchers. Data have been gathered through telephone interviews with 142 respondents. These data have been analyzed to answer research questions 1 and 2 .

\section{Preliminary results}

We analyzed data collected from 142 telephone interviews with 69 elderly respondents whose ages ranged from 55 to 87 and 73 young respondents with ages between 10 and 18 years [1 1]. We found remarkable differences between age groups in use, skills confidence and skills acquisition methods. The WWW is used by $97.3 \%$ of the young people against $71 \%$ of the elderly and the younger respondents perceived their skills, except for the use of email, higher than the elderly. The majority of the elderly respondents $(71.4 \%$ ) learned to go online and using email from receiving computer training whereas $80.3 \%$ of the younger people learned these internet activities themselves. 


\section{Ongoing and future work}

At the moment we are completing the second phase of the study in which course material was analyzed, training sessions observed and trainers and trainees interviewed.

In the next phase an inventory will be conducted of tasks that participants need to master if they want to engage in educational, social and institutional areas of participation through ICT.

From the interviews and observations a list of specific ICT tasks will be developed based on the framework of Van Deursen and Van Dijk [2]. They distinguish four types of digital skills:

Operational skills

- Operate an Internet browser

- Operate an online search engines

Formal skills

- Complete an online form

- Navigate on the Internet by recognising and using hyperlinks

- Maintaining a sense of location while navigating Information skills

- Locate, select and process information

- Evaluate the information source

Strategic skills

- Taking advantage of the Internet by goal oriented action and making decisions to gain personal benefits

A selection of respondents from the first phase will perform these tasks on their computer at home in presence of the researcher. Data resulting from the last phase can be linked with the findings from earlier phases. The results from this study will offer an insight in the way visually impaired people use their digital skills to participate in society. Furthermore it will form a foundation to help the support organizations improving and expanding the ICTrelated training they offer the young and elderly people with visual disabilities.

\section{References}

1. J.A.G.M. van Dijk. The deepening divide. Inequality in the Information Society. Sage Publications, London, 2005.

2. A.J.A.M. van Deursen, J.A.G.M. van Dijk. Digitale vaardigheden van Nederlandse Burgers. Een prestatiemeting van operationele, formele, informatie en strategische vaardigheden bij het gebruik van overheidwebsites. University Twente, Enschede, 2008.

3. Th. Van der Geest. Beyond accessibility. Compairing three web site usability test methods for people with impairments. In: A. Dearden \& L.Watts (eds), Proceedings of HCl 2004: Design for Life. Volume 2 pages 129-132, 2004.

4. Th. Van der Geest. Conducting usability studies with users who are elderly and have disabilities. In Technical Communication, 53, (1), pages 21-31, 2006.

5. M.F.Theofanos, J.C. Redish. Guidelines for accessible and usable websites: Observing users who work with screen readers. In Interactions, (10), (6), pages 36-51, 2003. 
6. M.F.Theofanos, J.C. Redish. Is One Site for All Feasible? In Technical Communication, 52 (1), pages 9-20, 2005.

7. K. Dobransky, E.Hargittai. The disability divide in internet access and use. In Information, Communication \& Society, 9, (3), pages 313-334, 2006.

8. N.L.Bayer, L.Pappas. Case history of blind testers of enterprise software. In Technical Communication, 53(1), pages 32-35, 2006.

9. E. Hargittai. How wide a web? Inequalities in accessing information online. PhD thesis, Sociology Department Princeton University, Princeton, 2003.

10. E. Hargittai. Survey Meausures of Web-Oriented Digital Literacy. Social Science Computer Review, 23(3), pages 371-379, 2005.

11. Carolina van Puffelen, Thea van der Geest, Hans van der Meij. The use of digital skills by visually disabled people to participate in society. In: Proceedings of the IADIS Multi Conference on Computer Science and Information Systems. Amsterdam, July, 2008.

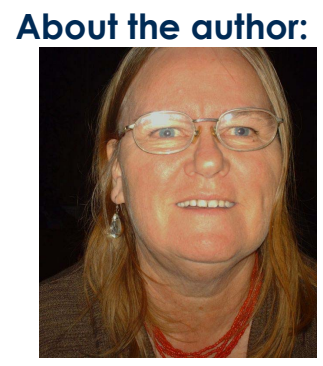

Carolina van Puffelen graduated with a Bachelor of Science in Education, Design, Multimedia and Management from the University of Twente in 2004. She was awarded a Master in Educational Science and Technology from the same university in 2005. She started her research project in 2007 at the Department of Technical and Professional Communication which specializes in web accessibility. Her research interests are in the area of human and computer interaction and inclusive technology. 